\title{
Evaluation of CYP2C9- and VKORC1-based pharmacogenetic algorithm for warfarin dose in Gaza-Palestine
}

\author{
Basim Mohammad Ayesh*,1, Ahmed Shaker Abu Shaaban² \& Abdalla Asaf Abed ${ }^{3}$ \\ ${ }^{1}$ Department of Laboratory Medical Sciences, Faculty of Applied Sciences, Alaqsa University, Gaza, Palestine \\ ${ }^{2}$ Abdul Aziz al Rantisi Paediatric Hospital Laboratory, Ministry of Health, Gaza, Palestine \\ ${ }^{3}$ Biology Department, Faculty of Science, Islamic University of Gaza, Gaza, Palestine \\ * Author for correspondence: Tel.: +970 8 2641601; +970 82641602 (Ext.: 1196); bm.ayesh@alaqsa.edu.ps
}

Aim: To evaluate applicability of CYP2C9*2, $* 3$ and $V K O R C 1-1639 G>A$ based algorithm to predict warfarin stable dose (WSD) in a group of Palestinian patients. Patients \& methods: Warfarin doses were retrospectively calculated for 101 Palestinian patients under warfarin therapy using three models. Performance of the three models was assessed in 47 patients found to take WSD. Results: Frequency of CYP2C9*2,*3 and VKORC1-1639G $>A$ alleles is $13.6,0.0$ and $46.5 \%$ respectively. The international warfarin pharmacogenetics consortium algorithm was more reliable (MAE $\left.=8.9 \pm 1.4 ; R^{2}=0.350\right)$ than both the clinical algorithm (MAE $=10.4 \pm 1.4 ; R^{2}=0.128 ;$ ) and the fixed-dose algorithm (MAE = 11.1 \pm 1.7$)$. Conclusion: The international warfarin pharmacogenetics consortium algorithm can be reliably applied for predicting the WSD in Palestinian population.

Lay abstract: The aim of this study was to evaluate applicability of an algorithm that is based on the patient genotype to predict the warfarin stable dose in a group of Palestinian patients. The international warfarin pharmacogenetics consortium algorithm was more reliable than both a clinical algorithm and a fixed-dose algorithm. The international warfarin pharmacogenetics consortium algorithm can be reliably applied for predicting the warfarin stable dose in Palestinian population.

First draft submitted: 27 September 2017; Accepted for publication: 22 November 2017; Published online: 10 January 2018

Keywords: allelic frequency • CYP2C9 • Gaza strip • IWPC algorithm • pharmacogenetics • vitamin K antagonist • VKORC1 • warfarin

Warfarin is a vitamin $\mathrm{K}$ antagonist used as the standard oral anticoagulant for venous and arterial thromboembolic disorders. A patient on warfarin therapy is at continuous risk for thrombosis or bleeding because of multiple environmental and genetic factors [1-6]. Among the key genetic causes of variability in response to warfarin are polymorphisms in the cytochrome P450, family 2, subfamily C, polypeptide 9 (CYP2C9) and the vitamin Kepoxide reductase complex 1 (VKORC1) genes [7-13]. The CYP2C9*2 allele (c.430 C > T; p.Arg144Cys; rs1799853) and *3 allele (c.1075A > C; p.Ile359Leu; rs1057910) are believed to dominantly impair the metabolism of S-warfarin by $30-40 \%$ and $80-90 \%$, respectively [10]. Furthermore, lower requirement of warfarin maintenance dose is associated with impaired VKORC1 expression because of a prevalent promoter single nucleotide polymorphism (c.-1639 $\mathrm{G}>$ A) $[12,14]$. Therefore, the average daily warfarin doses differ by race/ethnicity $[15,16]$. The international warfarin pharmacogenetics consortium (IWPC) has recommended an algorithm for estimating the initial warfarin weekly dose based on CYP2C9 and VKORC1 genotypes and some patient's clinical and anthropometric measures [17]. The algorithm has been recommended by the latest guidelines for warfarin treatment of a different range of conditions $[17,18]$.

In Gaza strip, warfarin is empirically administered to a wide range of patients with repeated dose adjustment until the target INR is reached. A $5 \mathrm{mg} /$ day warfarin dose is initially administered followed with a number of INR tests and dose adjustments. Attempts to reach a WSD are accompanied with a high risk of bleeding adverse effects. To the best of our knowledge, warfarin therapy has never been assessed in Gaza strip, neither has the prevalence 
of CYP2C9 and VKORC1 allelic variants been determined. Therefore, in this study we aimed at determining the applicability of the IWPC pharmacogenetic based algorithm for prediction of warfarin dose, depending on CYP2C9 and $V K O R C 1$ alleles among Palestinian population of Gaza strip.

\section{Materials \& methods}

\section{Patients \& sample collection}

The study population was recruited from the anticoagulation clinics of the European Gaza Hospital and Al-Shifa Hospital during a 3-month period. The recruited patients were under warfarin therapy.

Approximately, $2.5 \mathrm{ml}$ of venous blood were collected in EDTA tube from each participant and processed for genomic DNA extraction. Another $1.8 \mathrm{ml}$ peripheral blood were collected in tubes containing 3.2\% sodium citrate for prothrombin time (PT) and INR testing. Patients were assured for vitamin $\mathrm{K}$ free diet at least three days before blood sample collection.

\section{PT \& INR measurement}

Sodium citrate blood specimens were centrifuged at $1600-2000 \times g$ for $10 \mathrm{~min}$ to obtain platelet poor plasma. Prewormed $100 \mu \mathrm{l}$ of the plasma or controls were incubated with prewormed $200 \mu \mathrm{l}$ thromboplastin reagent (Dutch Diagnostics, Netherlands) at $37^{\circ} \mathrm{C}$. The time required for clot formation was recorded in seconds and the INR was calculated using the formula $\left(\mathrm{INR}=\left(\mathrm{PT}_{\text {patient }} / \mathrm{PT}_{\text {normal }}\right){ }^{\mathrm{ISI}}\right)$, where $\mathrm{PT}_{\text {normal }}$ is the mean value for normal patients in seconds (15.0 s as calculated in the study) and ISI is the International Sensitivity Index for the thromboplastin reagent (1.03 as set by the manufacturer). The targeted therapeutic range of INR was set at (2.0-3.0) for every patient except for three patients who have had mechanical heart valve replacement and needed their INR to fall between 2.5 and 3.5 , as clinically recommended [19].

\section{DNA extraction \& PCR/RFLP detection of CYP2C9*2, CYP2C9 *3 \& VKORC1 (1639G > A) allelic variants}

Genomic DNA was extracted from $300 \mu \mathrm{l}$ peripheral blood leukocytes using the Wizard Genomic DNA Extraction Kit (Promega, USA) according to the manufacturer recommendations.

The deficiency allele CYP2C9*2 was analyzed by amplification of a 454 bp fragment in exon 3 flanking the nucleotide substitution site, and AvaII restriction digestion [20]. The PCR reactions were carried out in $25 \mu \mathrm{l}$ volumes containing $2 \mu \mathrm{l}$ of extracted DNA, 10 pmol of each primer (5'-GTATTTTGGCCTGAAACCCATA-3' in forward direction and 5'-GGCCTTGGTTTTTCTCAACTC-3' in reverse direction) and $1 \times$ GoTaq Green master mix (Promega, USA). The cycling profile consisted of an initial denaturation step at $94^{\circ} \mathrm{C}$ for 5 min; followed by 35 cycles of $94^{\circ} \mathrm{C}$ for $60 \mathrm{~s}, 52^{\circ} \mathrm{C}$ for $45 \mathrm{~s}$ and $72^{\circ} \mathrm{C}$ for $60 \mathrm{~s}$ and a 10 -min final extension at $72^{\circ} \mathrm{C}$. The resulting $454 \mathrm{bp}$ product was digested for $1 \mathrm{~h}$ with $10 \mathrm{U} / \mu \mathrm{l} A v a \mathrm{II}$ at $37^{\circ} \mathrm{C}$ in the provided buffer and analyzed by electrophoresis in a 2.5\% agarose gel. AvaII cuts the PCR products of the wild-type allele into 397 and $57 \mathrm{bp}$ fragments.

The null allele CYP2C9*3 was analyzed, similar to CYP2C9*2, by amplifying a $105 \mathrm{bp}$ fragment from exon 7 flanking the nucleotide substitution site and $K p n \mathrm{I}$ restriction digestion [21]. The primer sequences were (5'TGCACGAGGTCCAGAGGTAC-3' in forward direction and 5'-ACAAACTTACCTTGGGAATGAGA-3' in reverse direction). The resulting 105 bp product was digested for $1 \mathrm{~h}$ with $10 \mathrm{U} / \mu \mathrm{K} K n \mathrm{I}$ in the provided buffer at $37^{\circ} \mathrm{C}$ and analyzed by electrophoresis on a 3.5\% agarose gel. KpnI cuts PCR products containing the mutant allele into 85 and $20 \mathrm{bp}$ fragments.

For detection of the VKORC1-1639G > A deficiency allele, the PCR reactions were carried out in $20 \mu \mathrm{l}$ volumes containing $2 \mu \mathrm{l}$ of extracted DNA, five pmol of each primer [22] (5'-GCCAGCAGGAGAGGGAAATA3 ' in forward direction and 5'-AGTTTGGACTACAGGTGCCT-3' in reverse direction) and $1 \times$ GoTaq Green master mix. The cycling profile consisted of an initial denaturation step at $94^{\circ} \mathrm{C}$ for $5 \mathrm{~min}$; followed with 30 cycles of $94^{\circ} \mathrm{C}$ for $60 \mathrm{~s}, 52^{\circ} \mathrm{C}$ for $60 \mathrm{~s}$, and $72^{\circ} \mathrm{C}$ for $60 \mathrm{~s}$; and a 5 -min final extension at $72^{\circ} \mathrm{C}$. The resulting $290 \mathrm{bp}$ product was digested for $16 \mathrm{~h}$ with $20 \mathrm{U} / \mu \mathrm{l} M s p \mathrm{I}$ in the provided buffer at $37^{\circ} \mathrm{C}$ and analyzed by electrophoresis in a 3.5\% agarose gel. MspI cuts the PCR products of the wild-type allele into 167 and 123 bp fragments.

\section{Data analysis}

Personal and clinical data were available for 99 participants and included the weekly dose of warfarin, duration under warfarin treatment, change in warfarin dose, warfarin-associated hemorrhage. Bleeding events were classified 
as minor (mild nosebleeds, bruise, microscopic hematuria, and mild gingival, conjunctival or anal bleeding) and major (gross hematuria, gastrointestinal bleeding requiring medical evaluation or blood transfusion) if they occurred at least once. The data were obtained from the medical record or from the patient himself.

The INR data were used to determine if the patient has imperially reached a WSD, in other words the patient remained on the same dose for at least three consecutive visits and had a target INR within the target range. Three warfarin dose prediction models were examined in terms of their ability to predict the WSD for each patient. The IWPC pharmacogenetic algorithm (PGx) depends on CYP2C9 and VKORC1 genotypes and other patients' anthropometric measures (age, height, weight, race, taking enzyme inducer and amiodarone) [17]. The clinical algorithm utilizes the same variables as the PGx model, but without the incorporation of genetic variables. The third model is based on a fixed-dose of $35 \mathrm{mg} /$ week.

To compare model performance, first, the mean absolute error (MAE) was determined by calculating the average of the absolute values of the differences between the WSD and the doses predicted by each model. Second, the coefficient of determination (R2) was calculated for each model using linear regression. Finally, the percentage of patients whose predicted warfarin dose was within $20 \%$ of the empirically reached stable therapeutic dose (Ideal) was determined. Similarly, the percentage of patients with predicted dose of at least $20 \%$ higher than the actual dose (overestimation) or at least $20 \%$ lower than the actual dose (underestimation) was also calculated. These values represent a difference of $1 \mathrm{mg}$ per day relative to the traditional starting dose of $5 \mathrm{mg}$ per day, a difference clinicians would be likely to define as clinically relevant [23]. The benefit of using a PGx algorithm over other algorithms was further verified with the number needed to genotype (NNG) analysis. The NNG is the average number of patients who need to be genotyped for one of them to benefit compared with a control. It is defined as the reciprocal of the absolute risk reduction (ARR), which is calculated as the absolute difference between the event rate (ER) for the PGx algorithm and the ER for the compared algorithm (clinical or fixed-dose). ER the probability of a bad event in other words (underestimation + overestimation)/total number of patients. The ideal NNG is one, and the higher the NNG, the less effective is the treatment.

Data were tabulated and analyzed using the Statistical Package for Social Science software version 17. The accuracy and completeness of all questions was assured by frequency distribution and cross tabulation for the entire data. The Chi square and $t$ tests were used as needed and $p$-value of $\leq 0.05$ were considered statistically significant. Means were presented \pm standard deviation.

\section{Results}

\section{Characteristics of the study population}

The characteristics of patients participating of the study are listed in Table 1. The study population consisted of 101 patients from the five Governorates of Gaza strip ( $42.6 \%$ males and $57.4 \%$ females). More than two thirds of patients were from Gaza Governorate, 16.2\% from Deir al-Balah (mid-zone) governorate, 8.1\% from north Gaza governorate, and about $9.1 \%$ from south the governorates (Khan Yunis \& Rafah). Their ages ranged from 16 to 76 years, with mean age of $48.8 \pm 14.4$ years $(50.0 \pm 13.8$ years for males and $48.0 \pm 15.0$ years for females). The average of body mass index of patients was $27.8 \pm 5.2 \mathrm{~kg} / \mathrm{m}^{2}$ where that of males was $27.2 \pm 5.0 \mathrm{~kg} / \mathrm{m}^{2}$ and that of females was $28.2 \pm 5.3 \mathrm{~kg} / \mathrm{m}^{2}$.

The patients were taking warfarin treatment because of thromboembolic events (50.5\%), cardiovascular disease $(41.4 \%)$ or both $(8.1 \%)$. It is worthy mentioning that $51.5 \%$ of patients were complaining from other chronic diseases as well. The average of INR of patients was $2.4 \pm 1.5$ (Table 4.1). There were $45.5 \%$ of patients suffering from warfarin-associated adverse effect and $54.5 \%$ were not.

\section{CYP2C9 \& VKORC1 genotype \& allelic frequency}

Only one patient (1\%) was homozygote for the CYP2C9*2 allele and 25 patients $(24.8 \%)$ were heterozygotes. The CYP2C9*3 allele was not detected and thus the remaining $74.2 \%$ of the study population were homozygotes for the wild-type allele $\left(C Y P 2 C 9^{*} 1\right)$ at the two polymorphic SNPs (Table 2). The calculated frequency of CYP2C9* 1 allele is $86.4 \%$ and of $C Y P 2 C 9^{*} 2$ allele is $13.6 \%$, and both alleles are in Hardy-Weinberg equilibrium (p-value $=0.473$ ). The genotypes for VKORC1-1639G > A were 48.5\% (GA), 21.8\% (AA) and 29.7\% (GG). Frequency of the susceptibility allele (A) was calculated to be $46.5 \%$ and that of the wild-type allele (G) was $53.5 \%$, and both alleles are in Hardy-Weinberg equilibrium ( $\mathrm{p}$-value $=0.8$ ). Different allelic combinations of both genes were obtained (Table 2). 
Table 1. Characteristics of the study population.

Gender (\%)

- Males

- Females

Age (years)

- Males

- Females

Governorate of residence (\%)

- North Gaza

- Gaza City

- Mid-zone

- Khan Younis

- Rafah

Body mass index $\left(\mathrm{kg} / \mathrm{m}^{2}\right)$

- Males $\left(\mathrm{kg} / \mathrm{m}^{2}\right)$

- Females $\left(\mathrm{kg} / \mathrm{m}^{2}\right)$

- Obese (\%)

- Overweight (\%)

- Normal weight (\%)

- Underweight (\%)

Type of disease (\%)

- Thromboembolic events

- Cardiovascular events

- Both

Average of INR

Bleeding (\%)

- Major event

- Minor event

- None

\section{4}

57.6

$48.8 \pm 14.4$

$50.0 \pm 13.8$

$48.0 \pm 15.0$

8.1

66.7

16.2

5.1

4.0

$27.8 \pm 5.2$

$27.2 \pm 5.0$

$28.2 \pm 5.3$

33.7

29.7

32.7

4.0

50.5

41.4

8.1

$2.4 \pm 1.5$

7

38.5

54.5

\begin{tabular}{|c|c|c|c|c|}
\hline & Genotype & Frequency & Percent & Allelic frequency \\
\hline \multirow[t]{4}{*}{ CYP2C9 } & $1 * / 1 *$ & 75 & 74.3 & $\begin{array}{l}\text { Allele }(* 1)=86.4 \% \\
\text { Allele }(* 2)=13.6 \%\end{array}$ \\
\hline & $1 * / 2 *$ & 25 & 24.8 & \\
\hline & $2 * / 2 *$ & 1 & 1.0 & \\
\hline & Total & 101 & 100.0 & \\
\hline \multirow[t]{4}{*}{ VKORC1 } & GG & 30 & 29.7 & $\begin{array}{l}\text { Allele }(G)=53.5 \% \\
\text { Allele }(A)=46.5 \%\end{array}$ \\
\hline & GA & 49 & 48.5 & \\
\hline & AA & 22 & 21.8 & \\
\hline & Total & 101 & 100.0 & \\
\hline \multirow[t]{8}{*}{ CYP2C9/VKORC1 } & *1*1/GG & 22 & 21.8 & \\
\hline & $* 1 * 1 / \mathrm{GA}$ & 35 & 34.7 & \\
\hline & $* 1 * 1 / \mathrm{AA}$ & 18 & 17.8 & \\
\hline & $* 1 * 2 / G G$ & 7 & 6.9 & \\
\hline & $* 1 * 2 / \mathrm{GA}$ & 14 & 13.9 & \\
\hline & $* 1 * 2 / \mathrm{AA}$ & 4 & 4.0 & \\
\hline & $* 2 * 2 / G G$ & 1 & 1.0 & \\
\hline & Total & 101 & 100.0 & \\
\hline
\end{tabular}

\section{Warfarin therapy}

By comparing the empirically adjusted warfarin dose for all participants (mean $=42.8 \pm 15.0 \mathrm{mg} / \mathrm{week}$ ) to that predicted by the IWPC PGx algorithm (mean $=35.9 \pm 69.6 \mathrm{mg} /$ week), $41.6 \%$ of the patients were found to receive empirically adjusted doses that are higher than predicted. Among those, $54.8 \%$ suffered at least one bleeding event compared with only $35.7 \%$ of those having equal or lower than predicted doses (Table 3 ). The relationship between bleeding events and warfarin dose is statistically significant as represented in Table 3 (p-value $=0.043$; Chi-Square $=6.285$ ). 
Table 3. Bleeding complications.

\begin{tabular}{|c|c|c|c|c|}
\hline \multirow[t]{2}{*}{ Bleeding event } & \multicolumn{3}{|c|}{ Given therapeutic dose (mg/week) ${ }^{\dagger}$} & \multirow[t]{2}{*}{ p-value } \\
\hline & Higher than calculated & Same as calculated & Lower than calculated & \\
\hline None & $19(34.5 \%)$ & $25(45.5 \%)$ & $11(20.0 \%)$ & 0.043 \\
\hline Yes & $23(52.3 \%)$ & $19(43.2 \%)$ & $2(4.5 \%)$ & \\
\hline Total & $42(42.4 \%)$ & $44(44.4 \%)$ & $13(13.1 \%)$ & \\
\hline
\end{tabular}

†The values are represented as frequency (valid percent). Data for two genotyped patients were missing. The three values were calculated using the IWPC algorithm.

\begin{tabular}{|c|c|c|c|c|c|}
\hline \multirow[t]{2}{*}{ Gene(s) } & \multirow[t]{2}{*}{ Alleles } & \multirow[t]{2}{*}{$\mathrm{N}$} & \multicolumn{2}{|c|}{ Given warfarin WSD ( $\mathrm{mg} /$ week) } & \multirow[t]{2}{*}{ p-value ${ }^{\dagger}$} \\
\hline & & & Mean & Std. Dev. & \\
\hline \multirow[t]{3}{*}{ CYP2C9 } & $1 * / 1 *$ & 34 & 42.6 & 13.8 & 0.520 \\
\hline & $1 * / 2 *$ & 13 & 39.4 & 17.5 & \\
\hline & Total & 47 & 41.7 & 14.8 & \\
\hline \multirow[t]{3}{*}{ VKORC1 } & GG & 15 & 51.2 & 15.9 & 0.004 \\
\hline & AA & 9 & 32.5 & 8.8 & \\
\hline & Total & 47 & 41.7 & 14.8 & \\
\hline \multirow[t]{2}{*}{ CYP2C9/VKORC } & $\begin{array}{l}* 1 * 1 / \mathrm{GG} \\
*^{*} 1 * 2 / \mathrm{GA} \\
* 1 * 1 / \mathrm{GA}\end{array}$ & 31 & 45.6 & 14.6 & 0.010 \\
\hline & $\begin{array}{l}* 1 * 2 / G G \\
* 1 * 1 / A A \\
* 1 * 2 / A A\end{array}$ & 16 & 34.1 & 12.4 & \\
\hline
\end{tabular}

${ }^{\dagger}$ The independent samples t-test was applied for comparing CYP2C9 and CYP2C9/VKORC groups; and the one-way ANOVA was applied for VKORC1 gene. The statistical power, computed using alpha $=0.05$, is 0.796 .

ANOVA: Analysis of variance; WSD: Warfarin stable dose.

Table 5. Comparison of three dose-prediction models.

\begin{tabular}{|lllll|}
\hline & Model & PGx & Clinical & Fixed-dose \\
\hline Regression $\pm \mathrm{SE}(\mathrm{mg} /$ week $)$ & & $8.9 \pm 1.4$ & $10.4 \pm 1.4$ & $11.1 \pm 1.7$ \\
\hline & $R$ & 0.592 & 0.358 & Not applicable \\
\hline & $\mathrm{R}^{2}$ & 0.350 & 0.128 & \\
\hline & $F$ & 24.233 & 6.611 & 0.014 \\
\hline
\end{tabular}

MAE: Mean absolute error; PGx: Pharmacogenetic algorithm; SE: Standard error.

\section{Relationship between genotype \& WSD}

Only 47 patients were found to take WSD and therefore, considered for further analysis of performance of the prediction models. Table 4 compares the mean empirically adjusted WSD according to CYP2C9 and VKORC1 genotypes. WSD was lower in case of homo- or heterozygosity for either or both genes. The difference was not statistically significant between $C Y P 2 C 9^{*} 2$ allele heterozygotes and the wild-type allele homozygotes (pvalue $=0.520$ ). On the other hand, the WSDs were significantly lower for patients carrying one or two copies of the VKORC1-A allele compared with homozygotes for the wild-type $-G$ allele (p-value $=0.004)$. The difference was also statistically significant between poor responders $\left({ }^{*} 1{ }^{*} 1 / G G,{ }^{*} 1{ }^{*} 2 / G A\right.$, and $\left.{ }^{*} 1{ }^{*} 1 / G A\right)$ and good responders $\left({ }^{*} 1{ }^{*} 2 / G G,{ }^{*}{ }^{*} 1 / A A\right.$ and ${ }^{*} 1{ }^{*} 2 / A A$ ) to warfarin (p-value $=0.010$ ).

\section{Performance of three dose-prediction models}

Comparisons of three models for dose prediction in the study cohort are summarized in Table 5. The PGx algorithm $(\mathrm{MAE}=8.9)$ provided dose estimates that were closer to empirically reached WSD than estimates derived by the clinical algorithm $(\mathrm{MAE}=10.4)$ and a fixed-dose approach $(\mathrm{MAE}=11.1)$. In general, there was a 


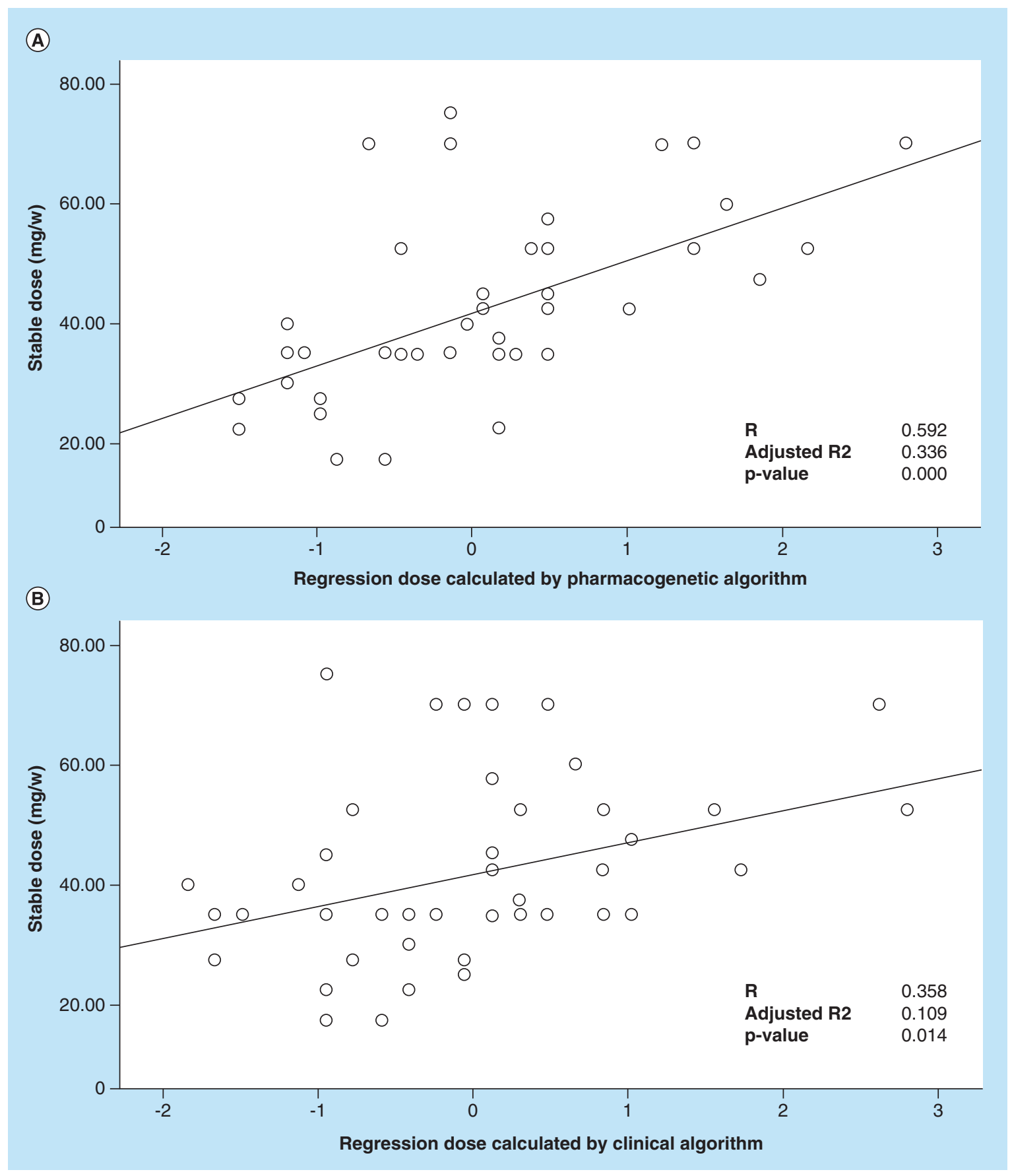

Figure 1. Linear regression analysis of warfarin stable dose versus predicted dose.

A scatter-plot of the correlation and regression between the empirically adjusted WSD and that predicted using (A) the PGx algorithm and (B) the clinical algorithm. Please note that some points have identical values and thus are superimposed in the graph, and therefore are darker.

PGx: Pharmacogenetic algorithm; WSD: Warfarin stable dose.

statistically significant correlation between the empirically reached WSD, and the pharmacogenetically predicted dose $\left(\mathrm{R}^{2}=0.350 ; \mathrm{p}\right.$-value $\left.=0.00\right)$, and to a lesser extent the clinically calculated $\left(\mathrm{R}^{2}=0.128 ; \mathrm{p}\right.$-value $\left.=0.014\right)$. The correlation was better when the CYP2C9 and VKORC1 genotype was included (Table 5 \& Figure 1).

The predicted warfarin doses were classified into three groups based on their deviation from the empirically reached WSD. As represented in Table 6, 68.1\% of the values calculated with the PGx algorithm were ideal, 
Table 6. Number needed to genotype analysis for pharmacogenetic algorithm versus clinical and fixed-dose algorithms.

\begin{tabular}{|llll|}
\hline Model & PGx & Clinical & Fixed-dose \\
\hline Within 20\% of WSD (ideal) & $32(68.1 \%)$ & $25(53.2 \%)$ & $21(44.7 \%)$ \\
\hline$<20 \%$ of WSD (underestimation) & $12(25.5 \%)$ & $12(25.5 \%)$ & $15(3.9 \%)$ \\
\hline$>20 \%$ of WSD (overestimation) & $3(6.4 \%)$ & $10(21.3 \%)$ & $11(23.4 \%)$ \\
\hline Total & 47 & 47 & 47 \\
\hline ER & 0.319 & 0.468 & 0.553 \\
\hline ARR (PGx vs clinical) & 0.149 & & \\
\hline ARR (PGx vs Fixed-dose) & 0.234 & & \\
\hline NNG (PGx vs clinical) & 6.7 & & \\
\hline NNG (PGx vs Fixed-dose) & 4.3 & \\
\hline ARR: Absolute risk reduction; ER: Event rate; NNG: Number needed to genotype; WSD: Warfarin stable dose. & \\
\hline
\end{tabular}

ARR: Absolute risk reduction; ER: Event rate; NNG: Number needed to genotype; WSD: Warfarin stable dose.

compared with $53.2 \%$ for the clinical algorithm and $44.7 \%$ in case of fixed calculation. The NNG for PGx algorithm versus the clinical or fixed-dose algorithms was low (6.7 and 4.3 respectively)

Event rate (ER): (Underestimation + overestimation)/total number of patients

Absolute risk reduction $(\mathrm{ARR})=\left|E R_{P G x}-E R_{\text {clinical }}\right|$

Number needed to Genotype (NNG): $1 / A R R$

\section{Discussion}

Warfarin therapy, the major anticoagulation therapy, is limited by interindividual variation affecting its initiation and maintenance doses [17,24]. As a complex phenotype, both genetic and nongenetic factors are associated with prolonged time to maintenance dose with proper target INR [25-27]. Patients carrying one or two copies of the CYP2C9*2, CYP2C9*3 or $V K O R C 1-1639 \mathrm{G}>\mathrm{A}$ polymorphic alleles are more sensitive to warfarin and require lower doses than those carrying the wildtype alleles [28]. To the best of our knowledge, no study has previously evaluated the Palestinian population for factors affecting warfarin dosing. Therefore, in this study, we determined the frequency of two CYP2C9 variants ( ${ }^{*} 2$ and *3) and one $V K O R C 1$ variant $(-1639 \mathrm{G}>\mathrm{A})$ in a cohort of Palestinian patients treated with warfarin, and evaluated the use of the IWPC algorithm for estimation of warfarin maintenance dose among the same patients.

The calculated frequency of CYP2C9*2, *3 and $V K O R C 1-1639 \mathrm{G}>\mathrm{A}$ alleles in our population is $13.6,0.0$ and $46.5 \%$ respectively. In comparison, the frequency of the three alleles is respectively $13.3,2.3$ and $42.4 \%$ in Saudi Arabia [29] and 15.4, 7.8 and 52.4\% in Lebanon [30]. In other native Palestinians, in Israel the frequencies were 21, 7 and 58\% in Moslems, and 12, 6 and 53\% in Druze [31]. The average worldwide frequency of the CYP2C9*2 allele is $5 \%$ ranging from $0 \%$ in east Asian to $12 \%$ in European populations [32]. Similarly, the average worldwide frequency of the CYP2C9*3 allele is also 5\%, ranging from $0 \%$ in Africans to $11 \%$ in south Asian populations [33]. However, the average worldwide frequency of the VKORC1-1639 A-allele is higher (36\%), with a minimum of $5 \%$ in African and a maximum of $88 \%$ in east Asian populations [34].

Presence of the $V K O R C 1-1639 \mathrm{G}>\mathrm{A}$ allele was found to be significantly associated with higher sensitivity to warfarin therapy in our population. This is evident from requirement of a lower WSD in case of homo- or heterozygous genotypes (Table 3). The same polymorphism was previously shown to be associated with decreased warfarin dosing in white people, African Americans and people of Asian descent [35-38]. On the other hand, the difference in maintenance warfarin dose was not statistically significant between CYP2C9 * 1 and *2 alleles. This is probably due to the low number of $* 2$ allele homozygotes and absence of $* 3$ allele carriers in our population. As we mentioned earlier, the ${ }^{*} 3$ allele is believed to be twice more influential in impairing $S$-warfarin metabolism than $* 2$ allele (80-90\% for *3 compared with 30-40\% for *2) [10]. The VKORC1 genotype alone was proposed to be sufficient for warfarin dose prediction in a cohort of Egyptian patients [39]. VKORC1-1639G $>$ A individually explained the greatest variance in dose in whites than blacks and Asians [40].

Previous studies have shown that genotype-based warfarin dosing significantly improved anticoagulation control in white populations [41]. On the other hand, performance of the genetic algorithm was worse than that of the clinical algorithm in African Americans [42]. Therefore, warfarin dosing algorithms should be evaluated in each respective ethnic population before being recommended [16]. In our study, we compared the PGx based algorithm recommended by the IWPC to the same algorithm but with no genotype data (clinical algorithm) and with a 
fixed dose of $35 \mathrm{mg} /$ week. The PGx algorithm provided dose estimates that were closer to empirically reached WSDs than estimates derived from the clinical and a fixed-dose algorithm. The PGx algorithm gave the least MAE. The pharmacogenetically estimated doses in most patients $(68.1 \%)$ had ideal retrospectively pharmacogenetically calculated warfarin doses compared with $53.2 \%$ for the clinical algorithm and $44.7 \%$ in case of fixed-dose model (Table 6). Furthermore, higher coefficient of determination was obtained in case of the PGx model $\left(R^{2}=0.350\right)$ than in case of the clinical model $\left(\mathrm{R}^{2}=0.128\right.$; Table 5 and Figure 1). Like many other populations [23,43-47] our data highlights the ability of IWPC PGx algorithm to predict warfarin initiation and maintenance dose in the Palestinian population. More support can be provided by the fact that in this study, NNG for PGx algorithm versus the clinical algorithm was low (6.7) which is even lower than that in IWPC study (13.2) [23] and other studies as well (e.g., 13.3 in Japanese patients) [48]. The NNG was even lower (4.3) for PGx algorithm versus fixed-dose. As previously established, the lower the NNG, the more effective is the prediction model [49].

Additionally, all patients participating in this study did not reach their target INR before at least 1 month from the start of treatment. Lengthy periods of dose adjustment are frequently experienced with patients starting warfarin therapy. During these periods, they become exposed to a high risk for bleeding and thromboembolism. In our study, the occurrence of at least one bleeding event was significantly higher among patients with higher warfarin dose than predicted by the IWPC algorithm compared with those having equal or lower than predicted doses ( $\mathrm{p}$-value $=0.027$; Table 3$)$.

The outcomes of the study may be limited by the small number of patients with stable warfarin dose (SWD) at the time of the study. We could not enroll more patients mainly because of the lack of their clinical data.

\section{Conclusion}

The relatively common VKORC1-A allele is significantly associated with lower WSD in our population. While CYP2C9*3 allele was not detected, the effect of $C Y P 2 C 9^{*} 2$ allele (frequency $=13.6 \%$ ) alone in lowering the WSD is not statistically significant.

The IWPC PGx algorithm for estimation of initial warfarin dose was found reliable in our population, and thus recommended over the empirical approach for adjustment of warfarin dose in indicated patients.

\section{Future perspective}

Although, the correlation between the IWPC algorithm and the WSD was very good, it was not perfect $(\mathrm{R}=0.592)$. This may indicate the presence of other determinants for the individual WSD. Therefore, more research is recommended to evaluate the role of other alleles of CYP2C9 and VKORC1 as possible determinants of WSD. Furthermore, more research is recommended involving a larger cohort of patients to establish a Palestinian population based algorithm for prediction of warfarin dose.

\section{Summary poimts}

Background

- The CYP2C9*2, CYP2C9*3 or VKORC1-1639G > A polymorphic alleles increase the individual's sensitivity to warfarin.

- Pharmacogenetic algorithms have been established to predict the proper warfarin stable dose based on these allele genotype.

- The main aim of the study was to determine the frequency of CYP2C9 variants $(* 2$ and $* 3)$ and VKORC1 variant $(-1639 \mathrm{G}>\mathrm{A})$, and to evaluate the ability of the international warfarin pharmacogenetics consortium (IWPC) algorithm to predict the proper warfarin stable dose in a group of Palestinian patients of Gaza strip.

Methods

- Warfarin dose predictions were retrospectively determined for a cohort of Palestinian patients under warfarin therapy.

- CYP2C9 and VKORC1 genotypes were determined and used beside other clinical and anthropometric variables to predict the doses using three models (the IWPC pharmacogenetic algorithm (PGx), a clinical algorithm and a fixed-dose calculation of $35 \mathrm{mg} /$ week).

- The performance of the three models was assessed using different statistical analyses.

Results

- CYP2C9*2, *3 and VKORC1-A alleles frequency in our population is $13.6,0.0$ and $46.5 \%$ respectively.

- Carriage of at least one VKORC1-A allele significantly reduced the warfarin stable dose $(p$-value $=0.004)$.

- The IWPC PGx is more reliable than both the clinical algorithm and the fixed-dose algorithm in predicting the warfarin stable dose in the Palestinian population. 
- Occurrence of at least one bleeding event was significantly higher among patients with higher warfarin dose than predicted by the IWPC algorithm compared with those having equal or lower than predicted doses.

Conclusion

- The IWPC PGx algorithm can be reliably applied in identifying Palestinian patients who require a low dosage of warfarin and are at greater risk of bleeding complications.

Author's contributions

B Ayesh designed and supervised on the molecular genetic studies, performed the statistical analysis, and drafted the manuscript. AA Shaaban carried out the molecular genetic studies and helped performing the statistical analysis. A Abed helped in supervision on the theoretical and practical work.

Financial disclosure

The authors have no relevant affiliations or financial involvement with any organization or entity with a financial interest in or financial conflict with the subject matter or materials discussed in the manuscript apart from those disclosed.

No writing assistance was utilized in the production of this manuscript.

Ethical conduct of research

The procedures of the study were approved by the local ethical committee of the Palestinian health research council according to the World Medical Association Declaration of Helsinki [50], and a verbal consent was obtained from the patients over 18 years or the parents of patients under 18 years old (one patient). All participants were informed of the study objectives, procedures and possible outcomes before they approved collection of their blood samples and personal and clinical information.

\section{Open access}

This work is licensed under the Creative Commons Attribution 4.0 License. To view a copy of this license, visit http://creativecomm ons.org/licenses/by/4.0/

\section{References}

Papers of special note have been highlighted as: $\bullet$ of interest; $\bullet \bullet$ of considerable interest

1 Schulman S, Beyth RJ. Risk of bleeding with long-term antithrombotic therapy in atrial fibrillation. Eur. Heart J. Suppl. 7(Suppl. C), C34-C40 (2005).

2 Lemesle G, Ducrocq G, Elbez Y et al. Vitamin K antagonists with or without long-term antiplatelet therapy in outpatients with stable coronary artery disease and atrial fibrillation: association with ischemic and bleeding events. Clin. Cardiol. 40(10), 932-939 (2017).

3 Santos PC, Soares RA, Strunz CM et al. Simultaneous use of amiodarone influences warfarin maintenance dose but is not associated with adverse events. J. Manag. Care Spec. Pharm. 20(4), 376-381 (2014).

4 Limdi NA, Brown TM, Yan Q et al. Race influences warfarin dose changes associated with genetic factors. Blood 126(4), 539-545 (2015).

5 Pautas E, Moreau C, Gouin-Thibault I et al. Genetic factors (VKORC1, CYP2C9, EPHX1, and CYP4F2) are predictor variables for warfarin response in very elderly, frail inpatients. Clin. Pharmacol. Ther. 87(1), 57-64 (2010).

6 Biss TT, Avery PJ, Brandão LR et al. VKORC1 and CYP2C9 genotype and patient characteristics explain a large proportion of the variability in warfarin dose requirement among children. Blood 119(3), 868-873 (2012).

7 Scordo MG, Pengo V, Spina E, Dahl ML, Gusella M, Padrini R. Influence of CYP2C9 and CYP2C19 genetic polymorphisms on warfarin maintenance dose and metabolic clearance. Clin. Pharmacol. Ther. 72(6), 702-710 (2002).

8 Limdi N, Goldstein J, Blaisdell J, Beasley T, Rivers C, Acton R. Influence of CYP2C9 Genotype on warfarin dose among African American and European Americans. Pers. Med. 4(2), 157-169 (2007).

9 Limdi NA, Wiener H, Goldstein JA, Acton RT, Beasley TM. Influence of CYP2C9 and VKORC1 on warfarin response during initiation of therapy. Blood Cells Mol. Dis. 43(1), 119-128 (2009).

10 Lee CR, Goldstein JA, Pieper JA. Cytochrome P450 2C9 polymorphisms: a comprehensive review of the in-vitro and human data. Pharmacogenetics 12(3), 251-263 (2002).

11 Rieder MJ, Reiner AP, Gage BF et al. Effect of VKORC1 haplotypes on transcriptional regulation and warfarin dose. N. Engl. J. Med. 352(22), 2285-2293 (2005).

12 Wang D, Chen H, Momary KM, Cavallari LH, Johnson JA, Sadee W. Regulatory polymorphism in vitamin K epoxide reductase complex subunit 1 (VKORC1) affects gene expression and warfarin dose requirement. Blood 112(4), 1013-1021 (2008).

13 John JM, Herrington DM. Maintenance warfarin dose varies according to two haplotypes of the vitamin K epoxide reductase gene. Future Cardiol. 2(1), 29-32 (2006). 
14 Rieder MJ, Reiner AP, Gage BF et al. Effect of VKORC1 haplotypes on transcriptional regulation and warfarin dose. N. Engl. J. Med. 352(22), 2285-2293 (2005).

15 Kaye JB, Schultz LE, Steiner HE, Kittles RA, Cavallari LH, Karnes JH. Warfarin pharmacogenomics in diverse populations. Pharmacotherapy 37(9), 1150-1163 (2017).

16 Kubo K, Ohara M, Tachikawa M et al. Population differences in S-warfarin pharmacokinetics among African Americans, Asians and whites: their influence on pharmacogenetic dosing algorithms. Pharmacogenomics J. 17(6), 494-500 (2016).

17 Johnson JA, Gong L, Whirl-Carrillo M et al. Clinical pharmacogenetics implementation consortium guidelines for CYP2C9 and VKORC1 genotypes and warfarin dosing. Clin. Pharmacol. Ther. 90(4), 625-629 (2011).

- The international warfarin pharmacogenetics consortium algorithm for estimating the initial warfarin weekly dose based on CYP2C9 and VKORC1 genotypes can be found in this article.

18 Shaw K, Amstutz U, Kim RB et al. Clinical practice recommendations on genetic testing of CYP2C9 and VKORC1 variants in warfarin therapy. Ther. Drug Monit. 37(4), 428-436 (2015).

- The latest recommendations for warfarin theapy based on CYP2C9 and VKORC1 genotypes.

19 Guyatt GH, Akl EA, Crowther M et al. Executive summary: antithrombotic therapy and prevention of thrombosis (9th Edition): American College of chest physicians evidence-based clinical practice guidelines. Chest 141(2 Suppl.), S7-S47 (2012).

20 Nowak-Gottl U, Dietrich K, Schaffranek D et al. In pediatric patients, age has more impact on dosing of vitamin K antagonists than VKORC1 or CYP2C9 genotypes. Blood 116(26), 6101-6105 (2010).

21 Aomori T, Yamamoto K, Oguchi-Katayama A et al. Rapid single-nucleotide polymorphism detection of cytochrome P450 (CYP2C9) and vitamin $\mathrm{K}$ epoxide reductase (VKORC1) genes for the warfarin dose adjustment by the SMart-amplification process version 2. Clin. Chem. 55(4), 804-812 (2009).

22 Sconce EA, Khan TI, Wynne HA et al. The impact of CYP2C9 and VKORC1 genetic polymorphism and patient characteristics upon warfarin dose requirements: proposal for a new dosing regimen. Blood 106(7), 2329-2333 (2005).

23 Consortium IWP. Estimation of the warfarin dose with clinical and pharmacogenetic data. N. Engl. J. Med. 2009(360), $753-764$ (2009).

24 White PJ. Patient factors that influence warfarin dose response. J. Pharm. Pract. 23(3), 194-204 (2010).

- Highlights the main patient related factors affecting warfarin dose.

25 Finkelman BS, French B, Bershaw L, Kimmel SE. Factors affecting time to maintenance dose in patients initiating warfarin. Pharmacoepidemiol. Drug Saf. 24(3), 228-236 (2015).

26 Finkelman BS, French B, Bershaw L et al. Predicting prolonged dose titration in patients starting warfarin. Pharmacoepidemiol. Drug Saf. 25(11), 1228-1235 (2016).

27 Garcia P, Ruiz W, Loza Munarriz C. Warfarin initiation nomograms for venous thromboembolism. Conchrane Database Syst. Rev. (7), Cd007699 (2013).

28 Dean L. Warfarin therapy and the genotypes CYP2C9 and VKORC1. In: Medical Genetics Summaries. Pratt V, Mcleod H, Dean L, Malheiro A, Rubinstein W (Eds). National Center for Biotechnology Information (US) Bethesda, MD (2012).

29 Alzahrani AM, Ragia G, Hanieh H, Manolopoulos VG. Genotyping of CYP2C9 and VKORC1 in the Arabic population of Al-Ahsa, Saudi Arabia. BioMed Res. Int. 2013, 315980 (2013).

30 Esmerian MO, Mitri Z, Habbal MZ et al. Influence of CYP2C9 and VKORC1 polymorphisms on warfarin and acenocoumarol in a sample of Lebanese people. J. Clin. Pharmacol. 51(10), 1418-1428 (2011).

31 Efrati E, Elkin H, Sprecher E, Krivoy N. Distribution of CYP2C9 and VKORC1 risk alleles for warfarin sensitivity and resistance in the Israeli population. Curr. Drug Saf. 5(3), 190-193 (2010).

32 Ensembl-A. Ensembl release 89. 2017(17/7/2017), (2017).

- Frequencies of different CYP2C9 alleles in different populations worldwide can be found here.

33 Ensembl-B. Ensembl release 89. 2017(17/7/2017), (2017).

- Frequencies of the VKORC1 alleles in different populations worldwide can be found here.

34 Ensembl-C. Ensembl release 89. 2017(17/7/2017), (2017).

35 Yuan HY, Chen JJ, Lee MT et al. A novel functional VKORC1 promoter polymorphism is associated with inter-individual and inter-ethnic differences in warfarin sensitivity. Hum. Mol. Gen. 14(13), 1745-1751 (2005).

36 Moyer TP, O'kane DJ, Baudhuin LM et al. Warfarin sensitivity genotyping: a review of the literature and summary of patient experience. Mayo Clin. Proc. 84(12), 1079-1094 (2009).

37 Razavi F, Zarban A, Hajipoor F, Naseri M. The allele frequency of CYP2C9 and VKORC1 in the Southern Khorasan population. Res. Pharm. Sci. 12(3), 211-221 (2017).

38 Schelleman H, Chen Z, Kealey C et al. Warfarin response and vitamin K epoxide reductase complex 1 in African Americans and Caucasians. Clin. Pharmacol. Ther. 81(5), 742-747 (2007). 
39 Ekladious SMM, Issac MSM, Sharaf SAE-A, Abou-Youssef HS. Validation of a proposed warfarin dosing algorithm based on the genetic make-up of Egyptian patients. Mol. Diagn. Ther. 17(6), 381-390 (2013).

40 Limdi NA, Wadelius M, Cavallari L et al. Warfarin pharmacogenetics: a single VKORC1 polymorphism is predictive of dose across 3 racial groups. Blood 115(18), 3827-3834 (2010).

41 Pirmohamed M, Burnside G, Eriksson N et al. A randomized trial of genotype-guided dosing of warfarin. N. Engl. J. Med. 369(24), 2294-2303 (2013).

42 Kimmel SE, French B, Kasner SE et al. A pharmacogenetic versus a clinical algorithm for warfarin dosing. N. Engl. J. Med. 369(24), 2283-2293 (2013).

43 Roper N, Storer B, Bona R, Fang M. Validation and comparison of pharmacogenetics-based warfarin dosing algorithms for application of pharmacogenetic testing. J. Mol. Diagn. 12(3), 283-291 (2010).

44 Bazan NS, Sabry NA, Rizk A, Mokhtar S, Badary O. Validation of pharmacogenetic algorithms and warfarin dosing table in Egyptian patients. Int. J. Clin. Pharm. 34(6), 837-844 (2012).

45 Takeuchi F, Kashida M, Okazaki O et al. Evaluation of pharmacogenetic algorithm for warfarin dose requirements in Japanese patients. Circ. J. 74(5), 977-982 (2010).

46 Marin-Leblanc M, Perreault S, Bahroun I et al. Validation of warfarin pharmacogenetic algorithms in clinical practice. Pharmacogenomics 13(1), 21-29 (2012).

47 Drozda K, Wong S, Patel SR et al. Poor warfarin dose prediction with pharmacogenetic algorithms that exclude genotypes important for African Americans. Pharmacogenet. Genomics 25(2), 73 (2015).

48 Takeuchi F, Kashida M, Okazaki O et al. Evaluation of pharmacogenetic algorithm for warfarin dose requirements in Japanese patients. Circ. J. 74(5), 977-982 (2010). Cook RJ, Sackett DL. The number needed to treat: a clinically useful measure of treatment effect. BMJ 310(6977), 452-454 (1995). Wma. World Medical Association Declaration of Helsinki: ethical principles for medical research involving human subjects. JAMA 310(20), 2191-2194 (2013). 
